\title{
Desain Sistem Klasifikasi Kelainan Jantung menggunakan Learning Vector Quantization
}

\author{
Endah Purwanti, Franky Chandra A.S., dan Pujiyanto \\ Departemen Fisika-FST, Universitas Airlangga \\ Kampus C Unair Mulyorejo, Surabaya 60115 \\ M. Arief Bustomi* \\ Jurusan Fisika FMIPA Intitut Teknologi Sepuluh Nopember \\ Kampus ITS Sukolilo, Surabaya 60111
}

\begin{abstract}
Intisari
Electrocardiograph (ECG atau EKG) merupakan alat diagnosis yang mengukur dan merekam aktifitas listrik jantung. Analisis sinyal EKG sering digunakan untuk mendiagnosis beberapa jenis kelainan jantung. Pada penelitian ini, kami merancang sistem jaringan syaraf tiruan untuk klasifikasi citra elektrikardiogram. Metode pemrosesan citra digunakan untuk ekstraksi fitur citra EKG dan proses klasifikasi menggunakan learning vector quantization. Beberapa data elektrokardiogram digunakan sebagai data pelatihan dan pengujian jaringan klasifikasi. Tiga jenis kelainan jantung dapat dideteksi oleh sistem. Hasil simulasi menunjukkan bahwa akurasi algoritma klasifikasi adalah sebesar 89\% yang terdiri dari 9 normal, 4 bradikardi, 8 takikardi dan 7 aritmia.
\end{abstract}

\begin{abstract}
Electrocardiograph (ECG) is a diagnostic tool that measures and records the heart's electrical activity. ECG signal analysis is often used to diagnose some types of heart defects. In this study, we designed a system of artificial neural networks for image classification electrocardiogram. Image processing method used for ECG feature extraction and image classification process using learning vector quantization. Some electrocardiogram data is used as training data and testing the network classification. Three types of cardiac abnormalities can be detected by the system. Simulation results show that the accuracy of the classification algorithm is composed by $89 \%$ of the normal 9,4 bradycardia, tachycardia 8 and 7 arrhythmias.
\end{abstract}

KATA KUNCI: electrocardiogram, Learning Vector Quantization (LVQ), image processing

\section{PENDAHULUAN}

Penyakit jantung merupakan penyebab nomor satu kematian di dunia. Di Indonesia angka kematian yang disebabkan serangan jantung mencapai 26 hingga 30 persen. Berdasarkan data yang dikemukakan World Heart Federation (WHF), penyakit jantung mencapai 29,1 persen atau sebanyak 17,1 juta pasien setiap tahunnya meninggal diseluruh dunia.

Salah satu perangkat bioinstrumen yang digunakan untuk mendeteksi adanya kelainan pada jantung adalah Electrocardiograph (ECG). Hasil pemeriksaan EKG adalah berupa citra yang disebut electrocardiogram [1]. Manfaat elektrokardiogram adalah dapat memperlihatkan adanya infark miokard dan iskemi miokard (jantung koronel), gangguan irama jantung atau arrhythmias, gangguan jantung karena penyakit sistemik dan gangguan karena pengaruh obat-obatan yang berpengaruh terhadap fungsi jantung $[2,3]$.

Salah satu cara yang banyak dilakukan untuk mengidentifikasi ada tidaknya kelainan jantung adalah dengan menggu-

*E-MAIL: a_bustomi@physics.its.ac.id nakan bantuan komputer untuk mengetahui karakteristik dari sinyal pada EKG tersebut. Seiring dengan semakin pesatnya perkembangan metode komputasi, penelitian mengenai ekstraksi pola sinyal EKG dan klasifikasi kelainan jantung telah banyak dilakukan oleh para peneliti.

Pada penelitian ini didesain sistem klasifikasi kelainan jantung berdasarkan citra digital electrocardiogram menggunakan metode jaringan saraf tiruan Learning Vector Quantization (LVQ). Adapun output jaringan terdiri dari 4 jenis yaitu kondisi jantung dengan kelainan bradikardi, kondisi jantung dengan kelainan aritmia, kondisi jantung normal dan kondisi jantung dengan kelainan takikardi.

\section{DASAR TEORI}

\section{Kelainan jantung}

Kelainan pada jantung adalah suatu kondisi yang menyebabkan jantung tidak dapat bekerja sebagaimana mestinya. Ada banyak macam kelainan pada jantung. Berikut adalah beberapa macam kelainan pada jantung yang sering terjadi: [1-6] 


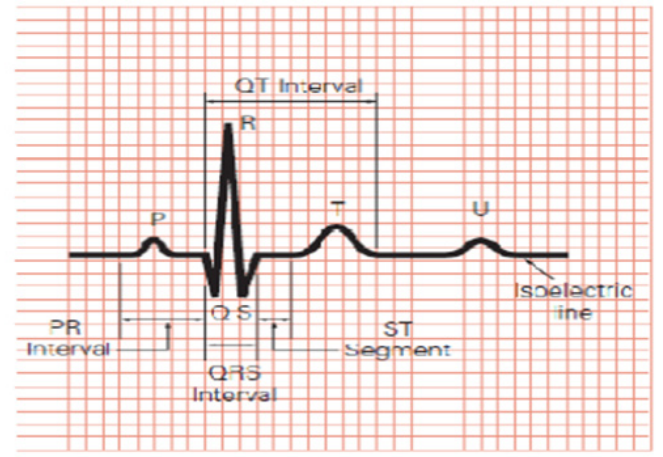

Gambar 1: Sinyal EKG

\section{Aterosklerosis}

Kelainan penyakit ini disebabkan adanya penebalan dinding arteri bagian dalam karena endapan plak (lemak, kolestrol) sehingga menghambat dan menyumbat pasokan darah.

2. Infark Miokard Akut

Infark Miokard Akut adalah kematian otot jantung karena penyumbatan pada arteri koroner.

3. Kardiomiopati

Kardiomiopati adalah kerusakan otot jantung sehingga menyebabkan dinding- dinding jantung tidak bergerak sempurna dalam menyedot dan memompa darah.

\section{Aritmia}

Aritmia adalah suatu keadaan dimana impuls listrik yang mengkoordinasikan denyut jantung seseorang tidak berfungsi dengan baik, sehingga dapat menyebabkan denyut jantung terlalu cepat (disebut takiaritmia jika denyut jantung $>100 /$ menit), terlalu lambat (disebut bradiaritmia jika denyut jantung $<60 \mathrm{kali} / \mathrm{menit}$ ) atau bahkan denyut jantung yang tidak teratur.

\section{Electrocardiogram}

Electrocardiogram merupakan grafik hasil yang dibuat oleh sebuah electrocardiograf, yang merekam aktivitas kelistrikan jantung dalam waktu tertentu.[2-4, 6, 7] Dasar atau prinsip kerja yang digunakan dalam alat ini adalah dengan memanfaatkan sifat konduktor listrik yang baik pada tubuh manusia. Sinyal EKG normal seperti pada Gambar 1.

\section{Pengolahan Citra Digital}

Pengolahan citra digital adalah suatu proses untuk memperbaiki kualitas citra atau memanipulasi suatu citra agar mudah diintepretasi oleh manusia. Beberapa proses penting dalam pengolahan citra adalah sebagai berikut [8-10]:

\section{Koreksi Gamma}

Bentuk umum dari transformasi gamma adalah:

$$
U^{\prime}=U^{\frac{1}{\gamma}}
$$

dengan U' dan U adalah citra setelah dan sebelum mengalami koreksi gamma, sedangkan $\gamma$ adalah faktor koreksi gamma, dengan kisaran $0<\gamma<1$.

\section{Segmentasi}

Segmentasi merupakan proses mempartisi citra menjadi beberapa daerah atau objek. Proses segmentasi dilakukan dengan membagi citra ke dalam beberapa kategori objek sesuai dengan pengelompokan tingkat keabuan yang terjadi pada histogram. Teknik ini sering disebut sebagai pengambangan (thresholding). Secara umum proses pengambangan citra grayscale untuk menghasilkan citra biner adalah sebagai

$$
g(x, y)=\left\{\begin{array}{l}
1, \text { jikaf }(x, y) \geq T \\
0, \text { jikaf }(x, y)<T
\end{array}\right.
$$

\section{Morfologi}

Operasi morfologi menggunakan dua input himpunan yaitu suatu citra (pada umumnya citra biner) dan suatu kernel/structuring elements (SE). Ada 2 operasi dasar morfologi yaitu dilasi dan erosi. Bila suatu objek (citra input) dinyatakan dengan A dan SE dinyatakan dengan B serta Bx menyatakan translasi B sedemikian sehingga pusat B terletak pada $\mathrm{x}$. Operasi dilasi A dengan B dapat dinyatakan sebagai

$$
D(A, B)=\left\{x: B_{x} \bigcap A \neq \Phi\right\}
$$

Operasi erosi dapat dinyatakan sebagai

$$
E(A, B)=\left\{x: B_{x} \subset X\right\}
$$

Manipulasi yang terjadi pada dilasi adalah konversi piksel-piksel latar belakang menjadi piksel-piksel objek dan manipulasi yang terjadi pada erosi adalah penghapusan piksel-piksel objek.

\section{Ekstraksi Fitur}

Fitur adalah karakteristik unik dari obyek. Karakteristik fitur yang baik sebisa mungkin memenuhi persyaratan sebagai berikut: discrimination, memperhatikan kompleksitas komputasi dalam memperoleh fitur, bersifat infarian terhadap transformasi dan jumlahnya sedikit.

\section{Jaringan Syaraf Tiruan (JST)}

JST merupakan representasi buatan dari otak manusia yang mencoba mensimulasikan proses pembelajaran pada otak manusia. JST terdiri dari beberapa simpul (node) yang merupakan elemen pemroses. Setiap simpul tersebut memodelkan sebuah sel saraf biologis (neuron). Hubungan antar simpul di capai dengan bobot koneksi (weight). Perubahan yang terjadi selama proses pembelajaran adalah perubahan nilai bobot. Secara skematis, model tiruan untuk sebuah sel jaringan syaraf (neuron) diperlihatkan pada Gambar 2 [11-13].

Salah satu metode untuk melakukan pembelajaran lapisan kompetitif yang terawasi adalah LVQ. Lapisan kompetitif ini 


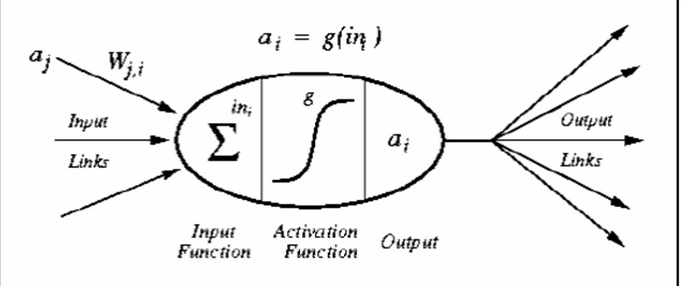

Gambar 2: Model Tiruan dari Neuron

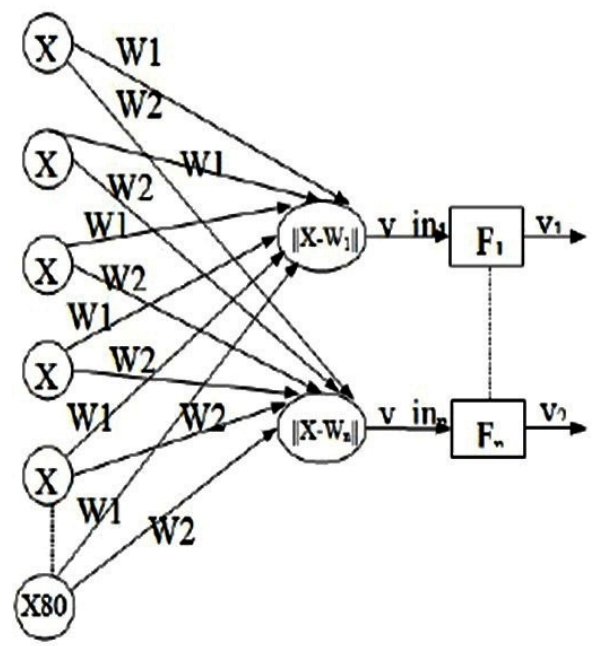

Gambar 3: Arsitektur LVQ

akan belajar secara otomatis untuk melakukan klasifikasi terhadap vector input yang diberikan. Kelas yang diberikan berdasarkan pada jarak vector tersebut. Jika ada dua vector yang mempunyai jarak yang berdekatan maka akan dikelompokkan menjadi satu kelas yang sama. Pada Gambar 3 diperlihatkan bentuk arsitektur jaringan dari LVQ [12].

\section{METODE PENELITIAN}

\section{Materi Penelitian}

Materi penelitian adalah sekumpulan berkas citra EKG pasien kondisi jantung normal, citra EKG pasien dengan kondisi jantung kelainan bradikardi, citra EKG pasien dengan kondisi jantung kelainan takikardi dan citra EKG pasien dengan kondisi jantung kelainan aritmia.

\section{Pemrosesan Citra}

Data citra EKG yang telah diubah kedalam bentuk digital kemudian diolah menggunakan metode pemrosesan citra untuk mendapatkan fitur citra EKG yang selanjutnya digunakan sebagai input pembelajaran sistem klasifikasi kelainan jantung. Secara garis besar, tahapan pemrosesan citra EKG disajikan pada Gambar 4.

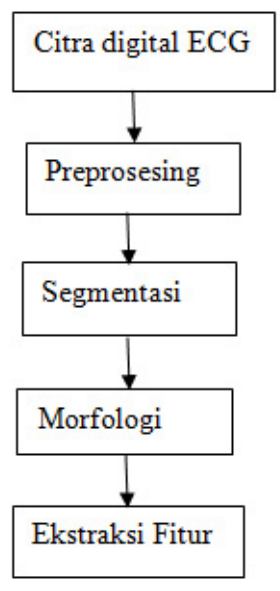

Gambar 4: Diagram Pemrosesan Citra EKG

1. Tahap preprosesing, proses awal yang dilakukan adalah memperbaiki kualitas citra EKG yaitu image brightness.

2. Tahap segmentasi, proses ini merupakan tahapan pemisahan grafik dengan latar belakangnya.

3. Tahap morfologi, proses morfologi merupakan proses untuk memperbaiki bentuk obyek yaitu grafik EKG yang diharapkan.

4. Tahap ekstraksi fitur, tahap ini merupakan tahap untuk mendapatkan nilai ordinat grafik EKG yang digunakan sebagai input sistem klasifikasi.

\section{Perancangan Perangkat Lunak}

Perancangan perangkat lunak sistem klasifikasi kelainan jantung dilakukan menggunakan metode LVQ. Algoritma LVQ adalah sebagai berikut:

1. Tetapkan:

Bobot (w), maksimum epoh (maxEpoh), learning rate $(\alpha)$, pengurangan learning rate $(\operatorname{Dec} \alpha)$, minimal learning rate $(\operatorname{Min} \alpha)$.

2. Masukan:

Input : $\mathrm{x}(\mathrm{i}, \mathrm{j})$

Target : Tk

3. Tetapkan kondisi awal:

epoh $=0$;

err $=1$;

4. Kerjakan jika : (epoh $\leq$ maxEpoh $)$ atau $(\alpha \leq$ eps $)$ 
- $\operatorname{epoh}=$ epoh +1

- Kerjakan untuk $\mathrm{i}=1$ sampai $n$

- Tentukan $\mathrm{j}$ sedemikian hingga $\|x-w j\|$ minimum (sebut sebagai $\mathrm{Cj}$ )

- Perbaiki wj dengan ketentuan: jika $\mathrm{T}=\mathrm{Cj}$ maka $w j($ baru $)=w j($ lama $)+$ $\alpha(\mathrm{x}-\mathrm{wj}$ (lama))

jika $\mathrm{T}$ tidak sama dengan $\mathrm{Cj}$ maka wj(baru $)=w j($ lama $)-\alpha(x-w j($ lama $))$

- Kurangi nilai $\alpha$

\section{Pengujian Perangkat Lunak}

Setelah melalui tahap training dan diperoleh bobot-bobot akhir (W), maka tahap selanjutnya adalah melakukan pengujian perangkat lunak dengan algoritma pengujian sebagai berikut:

1. Masukkan data citra EKG yang akan diuji

2. Ekstrak citra sehingga diperoleh nilai ordinat grafik EKG, misal $\mathrm{y}_{i j}$ dengan $\mathrm{i}=1,2, \ldots \mathrm{n}$ dan $\mathrm{j}=1,2, \ldots, \mathrm{m}$

3. Kerjakan untuk $\mathrm{i}=1$ sampai $\mathrm{n}$

- Tentukan j sedemikian hingga $|y i-W j|$ minimum

- J adalah kelas untuk yi

\section{HASIL DAN PEMBAHASAN}

\section{Pengolahan Data Masukan}

Data citra EKG yang digunakan sebagai data masukan diubah dalam bentuk digital menggunakan scanner. Data citra digital kemudian dicrop ROI sehingga diperoleh citra yang memiliki panjang 542 pixel.

\section{Pra-Pengolahan Citra}

Pada tahap pra-pengolahan dilakukan perbaikan kualitas citra menggunakan metode koreksi gamma. Hasil pra-pengolahan citra dengan beberapa nilai gamma diperlihatkan pada Gambar 5.

Pada faktor koreksi gamma 0,7 diperoleh citra yang cukup baik sehingga warna grafik masih cukup jelas dan dominan dibandingkan warna garis kertas.

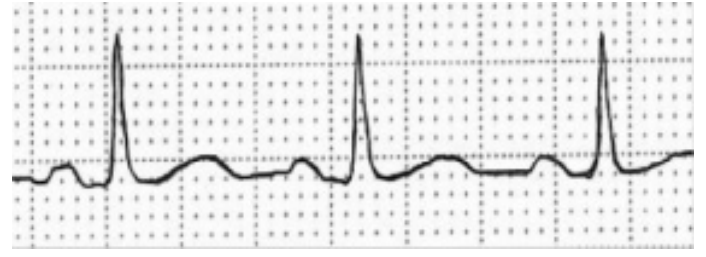

Gambar 5: Hasil Pra-pengolahan

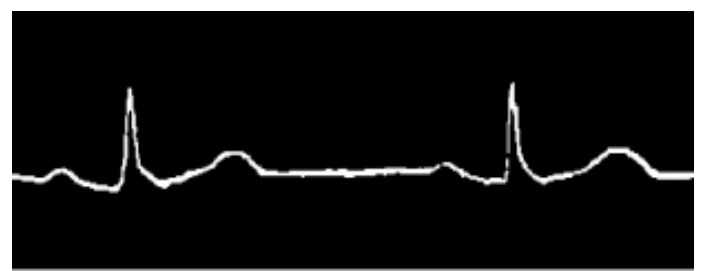

Gambar 6: Hasil Proses Segmentasi pada threshold sebesar 40

\section{Segmentasi}

Pada tahap ini dilakukan proses segmentasi untuk memperoleh objek/grafik yang terpisah dengan backgroundnya. Metode segmentasi yang digunakan dalam penelitian ini adalah metode thresholding dengan nilai threshold sebesar 40. Akan tetapi pada tahap ini, untuk beberapa data ada beberapa bagian objek/grafik yang hilang sehingga grafik menjadi terputus pada titik-titik tertentu (ditunjukkan pada Gambar 6).

\section{Morfologi}

Untuk memperbaiki bentuk grafik EKG, dilakukan operasi morfologi yaitu dilasi dan erosi. Hasil operasi morfologi diperlihatkan pada Gambar 7, dimana objek (grafik) yang semula terputus menjadi tersambung kembali dan ukuran objek sudah cukup baik( mendekati bentuk aslinya).

\section{Ekstraksi Fitur}

Pada penelitian ini, fitur citra yang diambil adalah nilai ordinat grafik EKG. Hasil visualisasi nilai ordinat grafik data di atas disajikan pada Gambar 8.

Nilai ordinat grafik tersebut merepresentasikan nilai perubahan potensial sebagai akibat aktifitas listrik jantung.

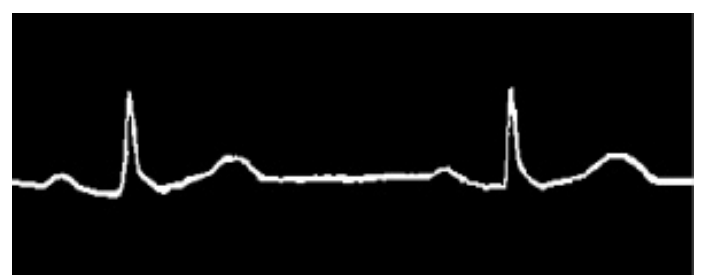

Gambar 7: Hasil Operasi Morfologi 


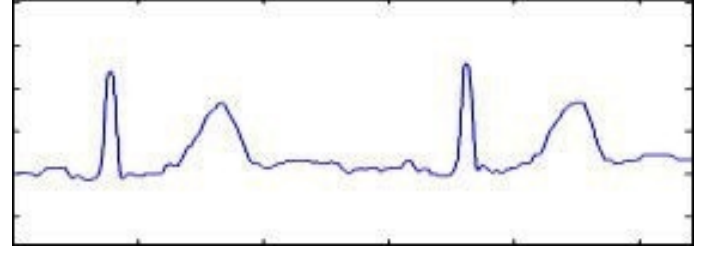

Gambar 8: Hasil Visualisasi fitur

TABEL I: Parameter jaringan LVQ

\begin{tabular}{lc}
\hline \hline Jumlah parameter input & 542 \\
\hline Jumlah pola target & 4 \\
\hline Variasi laju pelatihan $(\alpha)$ & 0,$5 ; 0,1 ; 0,015 ; 0,01$ \\
\hline Update laju pelatihan & $\alpha-\alpha^{*} \operatorname{dec} \alpha$ \\
\hline $\begin{array}{l}\text { Variasi pengurangan laju } \\
\text { pelatihan (dec } \alpha \text { ) }\end{array}$ & $1 ; 0,5 ; 0,1 ;$ \\
$\begin{array}{l}\text { Minimum laju pelatihan yang } \\
\text { diharapkan }\end{array}$ & 0,$015 ; 0,01 ; 0,0015$ \\
\hline Maksimum iterasi (epoch) & 0,001 \\
\hline \hline
\end{tabular}

\section{Pelatihan Jaringan Syaraf Tiruan LVQ}

Rekapitulasi parameter jaringan LVQ disajikan pada Tabel 1. Pada penelitian ini, untuk mendapatkan parameter optimal jaringan LVQ dilakukan beberapa variasi laju pelatihan $(\alpha)$ dan pengurangan laju pelatihan $(\operatorname{dec} \alpha)$. Pada laju pelatihan $(\alpha)$ sebesar 0,5 dengan variasi pengurangan laju pelatihan (dec $\alpha$ ) sebesar 0,$0015 ; 0,01 ; 0,015 ; 0,1 ; 0,3$ sampai 0,5 , tingkat akurasi meningkat secara signifikan. Akan tetapi pada ( $\operatorname{dec} \alpha$ ) sebesar 0,7 dan 1, tingkat akurasi jaringan terus menurun. Hal ini juga terjadi pada variasi laju pelatihan yang lain, dimana tingkat akurasi meningkat sebanding dengan kenaikan dec $\alpha$ sampai pada nilai optimum kemudian mengalami penurunan. Tingkat akurasi tertinggi diperoleh sebesar $94,74 \%$ pada parameter optimal jaringan LVQ yaitu laju pelatihan $(\alpha)$ sebesar 0,1 dan pengurangan laju pelatihan $(\operatorname{dec} \alpha)$ sebesar 0,1 .

Melalui pelatihan jaringan dan dengan mengambil parameter optimal $\alpha$ dan dec $\alpha$, diperoleh bobot-bobot akhir pelatihan yang selanjutnya digunakan untuk melakukan pengujian yaitu klasifikasi kelainan jantung.

\section{Pengujian Jaringan Syaraf Tiruan LVQ}

Citra EKG yang digunakan dalam pengujian jaringan LVQ berjumlah 28 buah data. Data tersebut terdiri dari 4 data citra EKG dengan kelainan bradikardi, 7 data citra EKG dengan kelainan aritmia, 9 data citra EKG kondisi jantung normal dan 8 data citra EKG dengan kelainan takikardi. Hasil pengujian jaringan LVQ menunjukkan bahwa keberhasilan kemampuan klasifikasi untuk data uji dengan jenis kelainan bradikardi adalah sebesar $100 \%$, untuk data uji dengan jenis kelainan aritmia juga sebesar $100 \%$, untuk data uji kondisi jantung normal sebesar $78 \%$ (2 dari 9 data tidak sesuai), dan untuk data uji dengan jenis kelainan takikardi adalah sebesar $88 \%$ ( 1 dari 8 data tidak sesuai). Tingkat keberhasilan sistem klasifikasi menggunakan metode LVQ untuk keseluruhan data uji adalah sebesar $89 \%$.

\section{SIMPULAN}

Beberapa hal yang dapat disimpulkan dari penelitian ini adalah :

1. Fitur ordinat grafik EKG dapat diperoleh melalui beberapa tahap pemrosesan citra antara lain koreksi gamma dengan faktor koreksi $\gamma=0,7$; segmentasi dengan threshold $\Phi=40$; morfologi dilasi dengan SE square berukuran 3 x 3 dan morfologi erosi dengan SE square berukuran $2 \times 2$.

2. Proses pelatihan jaringan LVQ berjalan cukup baik dengan tingkat akurasi jaringan sebesar 94,74\% pada laju pelatihan $(\alpha)$ sebesar 0,1 dan pengurangan laju pelatihan $(\operatorname{dec} \alpha)$ sebesar 0,1 .

3. Pada hasil pengujian, jaringan LVQ mampu mengklasifikasi kelainan bradikardi sebesar $100 \%$, kelainan aritmia sebesar $100 \%$, kondisi jantung normal sebesar $78 \%$ dan kelainan takikardi sebesar $88 \%$. Tingkat keberhasilan sistem klasifikasi secara keseluruhan data uji adalah sebesar $89 \%$.
[1] S. Pratanu, Buku Ajar Ilmu Penyakit Dalam (FK UI. Jilid 1 edisi ke-3.(halaman 88-934), Jakarta, 1999).

[2] K. Dubowik, Automated Arrhythmia Analysis - An Expert System for an Intensive Care Unit (New Jersey: Prentice-Hall, 1999).

[3] L. Schamroth, An Introduction to electrocardiography (Blackwell Scientific Publication, Oxford, 1990).

[4] E.J. Berbari, Principle of Electrocardiography: The Biomedical Engineering Handbook (CRC Press LCC, 2000).

[5] G.Q. Gao, Computerized Detection and Classification of Five Cardiac Condition (Auckland university of technology, New Zealand, 2003).

[6] Jondri dan A. Rizal, Deteksi Otomatis Kelainan Jantung Meng- gunakan Hidden Markov Model (HMM) (Institut Teknologi Telkom, Bandung, 2010).

[7] Endarko, dkk., Aplikasi Pengolahan Citra Elektrokardiograf dan Jaringan Saraf Tiruan untuk Identifikasi Penyakit Jantung Koroner, Jurnal Fisika dan Aplikasinya, 2(2), 0602011-0602018 (2006).

[8] D. Putra, Sistem Biometrika: Konsep Dasar Teknik Analisis Citra (Penerbit Andi, Jogjakarta, 2008).

[9] Nurdin dan D. Triwulandari, Konsep Pengolahan Citra Digital dan Ekstrasi fitur (Graha Ilmu, Jogjakarta, 2010).

[10] W.K. Pratt, Digital Image Processing (John Wiley and Sons, Hoboken, New Jersey, 2007). 
[11] G. Dhaneswara, S. Moertini, Veronica, Jaringan saraf tiruan propagasi balik Untuk Klasifikasi Data, Jurnal Integral, 9(3), November (2004)

[12] S. Kusumadewi, Membangun Jaringan Syaraf Tiruan Menggunakan Matlab dan Excellink (Graha Ilmu, edisi 1. Jogjakarta,
2004).

[13] R.M. Subekti, dkk., Karakteristik Jaringan Syaraf Tiruan untuk Analisis Aktivasi Neutron (Pusat Pengembangan Teknologi Reaktor Riset (P2TRR), BATAN, Serpong, Tangerang, 2005). 